\title{
Proteinograma e teores de cobre, ferro e zinco no soro sanguíneo de ovelhas da raça Santa Inês com mastite experimental por Staphylococcus aureus ${ }^{1}$
}

\author{
Nivaldo de Azevêdo Costa², Luis Carlos Valeriano Simão², Rogério Adriano \\ dos Santos ${ }^{2}$, José Augusto Bastos Afonso ${ }^{3}$, José Jurandir Fagliari ${ }^{4}$, Elyzabeth \\ da Cruz Cardoso ${ }^{5}$, Pierre Castro Soares ${ }^{6}$ e Carla Lopes de Mendonça ${ }^{3^{*}}$
}

\begin{abstract}
Costa N.A., Simão L.C.V., Santos R.A., Afonso J.A.B., Fagliari J.J., Cardoso E.C., Soares P.C. \& Mendonça C.L. 2010. [Proteinogram and serum concentrations of copper, iron and zinc in Santa Inês ewes with Staphylococcus aureus experimentally induced mastitis.] Proteinograma e teores de cobre, ferro e zinco no soro sanguíneo de ovelhas da raça Santa Inês com mastite experimental por Staphylococcus aureus. Pesquisa Veterinária Brasileira 30(5):435-442. Clínica de Bovinos, Campus Garanhuns, Universidade Federal Rural de Pernambuco, Avenida Bom Pastor s/n, Boa Vista, Caixa Postal 152, Garanhuns, PE 55292-901, Brazil. E-mail: carlalopes.mendonca@gmail.com

The aim of the present study was to evaluate the effect of Staphylococcus aureus experimentally induced mastitis on proteinogram and serum concentrations of cupper, iron and zinc levels of Santa Ines primiparous ewes. The right mammary gland of ten healthy ewes was inoculated with $1,0 \times 10^{4} \mathrm{UFC} / \mathrm{mL}$ of $S$. aureus. Clinical examination and determination of serum concentrations of proteins by electrophoresis in polyacrylamide gel (SDS-PAGE), cupper, iron and zinc, as well plasma level of fibrinogen were measured before the inoculation (control) and 12h, 24h, 36h, 48h, 60h, 72h, 84h, 96h, 108h, 120h, $132 \mathrm{~h}, 168 \mathrm{~h}, 180 \mathrm{~h}, 288 \mathrm{~h}$ and $336 \mathrm{~h}$ after bacteria inoculation. All animals experimentally infected presented clinical mastitis and subsequent loss of mammary gland function. The electrophoretogram allowed the identification of 23 proteins with molecular weights (MW) ranged from 26.000 to 185.000 daltons (Da) including acute-phase proteins, IgG and IgA. A significant increase $(P<0,05)$ in haptoglobin, ceruloplasmin, IgG and IgA concentrations was observed. Antitrypsin and acid glicoprotein concentrations did not alter. The levels of iron and zinc decreased and the cupper concentration increased. A positive correlation between plasma fibrinogen and serum ceruloplasmin $(r=0.74)$, haptoglobin $(r=0.62)$ and IgA ( $r=0.62)$ was also identified. Results showed the importance of ceruloplasmin and haptoglobin as acute-phase proteins in ewes with intramammary infections and confirms fibrinogen as an inflammatory marker because its high correlation with specific proteins. The alterations in the serum levels of $\mathrm{Cu}, \mathrm{Fe}$ and $\mathrm{Zn}$ suggest the action of inflammatory mediators triggered by $S$. aureus.
\end{abstract}

INDEX TERMS: Intramammary infection, ruminants, Gram positive, acute-phase proteins, SDSPAGE, oligoelements.

\footnotetext{
${ }^{1}$ Recebido para publicação em 9 de setembro de 2009.

Aceito para publicação em 4 de janeiro de 2010.

2 Programa de Pós-Graduação em Ciência Veterinária, Universidade Federal Rural de Pernambuco (UFRPE), Av. Dom Manuel de Medeiros s/n, Dois Irmãos, Recife, PE 52171-030, Brasil.

${ }^{3}$ Clínica de Bovinos, Campus Garanhuns, UFRPE, Av. Bom Pastor s/n, Boa Vista, Cx. Postal 152, Garanhuns, PE 55292-901. *Autor para correspondência: carlalopes.mendonca@gmail.com
}

\footnotetext{
${ }^{4}$ Departamento de Clínica e Cirurgia Veterinária, Faculdade de Ciências Agrárias e Veterinárias, Universidade Estadual Paulista Júlio de Mesquita Filho (Unesp), Campus de Jaboticabal, Via de Acesso Prof. Paulo Donato Castellane s/n, Jaboticabal, SP 14884-900, Brasil.

${ }^{5}$ Faculdade de Medicina Veterinária, Universidade Federal Fluminense (UFF), Rua Vital Brazil Filho 64, Santa Rosa, Niterói, RJ 24230-340, Brasil.

${ }^{6}$ Departamento de Medicina Veterinária, Universidade Federal Rural de Pernambuco(UFRPE), Recife, PE.
} 
RESUMO.- Este estudo teve por objetivo avaliar o proteinograma e os teores de cobre, ferro e zinco no soro sangüíneo de ovelhas com mastite induzida por cepa de campo de Staphylococcus aureus. Foram utilizadas 10 oveIhas da raça Santa Inês, primíparas, recém-paridas, com aproximadamente dois anos de idade e bom estado nutricional. Inoculou-se na metade direita da glândula mamária $1,0 \times 10^{4} \mathrm{UFC} / \mathrm{mL}$ da bactéria, enquanto que a metade esquerda serviu como controle. Os animais foram acompanhados diariamente e a partir do diagnóstico clínico de mastite, procedeu-se colheita do material para realização do proteinograma sérico em gel de poliacrilamida contendo dodecil sulfato de sódio (SDS-PAGE) e para determinação do teor plasmático de fibrinogênio e das concentrações séricas de cobre, ferro e zinco em 16 momentos a saber: antes da inoculação (controle) e $12 \mathrm{~h}$, $24 \mathrm{~h}, 36 \mathrm{~h}, 48 \mathrm{~h}, 60 \mathrm{~h}, 72 \mathrm{~h}, 84 \mathrm{~h}, 96 \mathrm{~h}, 108 \mathrm{~h}, 120 \mathrm{~h}, 132 \mathrm{~h}, 168 \mathrm{~h}$, $180 \mathrm{~h}, 288 \mathrm{~h}$ e $336 \mathrm{~h}$ após a inoculação (p.i.). Todas as oveIhas apresentaram quadro clínico de mastite, com perda da funcionalidade da glândula mamária. O proteinograma permitiu a identificação de 23 proteínas, cujos pesos moleculares (PM) variaram de 26.000 a 185.000 dáltons (Da), incluindo proteínas de fase aguda, $\lg G$ e $\lg A$. Notou-se aumento significativo nas concentrações de haptoglobina e ceruloplasmina, assim como de IgG e IgA. Não se constatou alteração nos teores de antitripisina e de glicoproteína ácida .Verificou-se diminuição nos teores de ferro e zinco e elevação na concentração de cobre. Constatou-se correlação positiva entre o teor plasmático de fibrinogênio e as concentrações séricas de ceruloplasmina $(r=0,74)$, a haptoglobina $(r=0,62)$ e $\lg A(r=0,62)$. Estes resultados mostram a importância das proteínas de fase aguda ceruloplasmina e haptoglobina como indicadores auxiliares da infecção intramamária de ovelhas, assim como ratifica a relevância do fibrinogênio como marcador inflamatório em razão de sua alta correlação com as proteínas especificas. As alterações nas concentrações séricas de $\mathrm{Cu}$, $\mathrm{Fe}$ e $\mathrm{Zn}$ sugerem a ação de mediadores inflamatórios, estimulados por $S$. aureus.

TERMOS DE INDEXAÇÃO: Infecção intramamária, ruminantes, Gram positivo, proteínas de fase aguda, SDS-PAGE, oligoelementos.

\section{INTRODUÇÃO}

O interesse pelo estudo da mastite na espécie ovina tem aumentado nos últimos anos. Nos casos agudos, as oveIhas podem morrer no pico da lactação, com prejuízo no desenvolvimento do lactente, podendo acarretar a morte do borrego. O problema se agrava em razão dos custos adicionais com a utilização de sucedâneos de leite, bem como o descarte prematuro de fêmeas com mastite crônica, tendo um grande impacto econômico para o criador, quando comparado aos efeitos na vaca e na cabra (Menzies \& Ramanoon 2001, Oliveira et al. 2007).

No Brasil, Staphylococcus aureus é relatado como o principal agente etiológico da mastite aguda, acarretando transtornos sistêmicos e locais, inclusive a perda do pa- rênquima mamário (Oliveira 2007). A disponibilidade de ferramentas para a vigilância da saúde dos rebanhos pode ser um componente útil em um programa de sanidade, o que requer a identificação de novos indicadores confiáveis de infecção. Várias técnicas já estão bem estabelecidas no diagnóstico de mastite, no entanto, a quantificação das proteínas de fase aguda (PFA) pode não apenas indicar a presença de uma doença inflamatória ativa, mas também indicar o prognóstico ou monitorar a resposta do indivíduo à terapia (Eckersall 2001, Ganheim et al. 2007). Grönlund et al. (2003) constataram que o aumento da concentração de PFA precede o aumento da contagem de células somáticas no leite de vacas com mastite clínica, sendo importante biomarcador de prognóstico.

Alterações nos teores séricos de alguns minerais, como cobre $(\mathrm{Cu})$, ferro $(\mathrm{Fe})$ e zinco $(\mathrm{Zn})$ são relatadas como consequências de enfermidades infecciosas de ruminantes, entre as quais a mastite (Corrigal et al. 1976, Sandholm et al. 1995, Mendonça et al. 2005). No Brasil, os estudos experimentais referentes à resposta inflamatória da glândula mamária de ovelhas e sua repercussão sistêmica são escassas. Neste contexto, a avaliação de biomarcadores preditivos de reação inflamatória, bem como de elementos traços na condição clínica de mastite na espécie ovina revestem-se de grande importância, uma vez que podem auxiliar na definição do diagnóstico e no monitoramento terapêutico da doença da glândula mamária. Este estudo teve por objetivo avaliar o perfil protéico, incluindo as proteínas de fase aguda e as concentrações de cobre, ferro e zinco no soro de ovelhas após a infecção experimental por $S$. aureus.

\section{MATERIAL E MÉTODOS}

Animais, manejo e alimentação. Foram utilizadas dez ovelhas da raça Santa Inês, primíparas, recém paridas (a partir de 15 dias após o parto), com aproximadamente dois anos de idade, mantidas em aprisco, recebendo dieta composta de feno de tifton (Cynodon sp.), capim elefante (Pennisetum purpureum), concentrado (aprox. 200g/animal/dia), sal mineral e água à vontade. Os borregos foram separados de suas mães logo após o nascimento, depois de mamarem colostro. As ovelhas eram ordenhadas manualmente duas vezes ao dia (manhã e tarde), seguindo um rigoroso manejo higiênico-sanitário, conforme recomendado por Fonseca \& Santos (2001).

Delineamento experimental. Previamente à inoculação da glândula mamária com Staphylococcus aureus foram obtidos os dados clínicos e laboratoriais mediante três colheitas de sangue, com intervalos de $24 \mathrm{~h}$, sempre pela manhã, com finalidade de estabelecer um valor médio para cada uma das variáveis estudadas, caracterizando o momento controle. $\mathrm{Na}$ manhã seguinte, após a terceira colheita, a glândula mamária direita foi inoculada com 1,0x104UFC/mL da bactéria, enquanto a glândula esquerda serviu como controle. A cepa empregada foi isolada de um caso clínico de mastite em ovelha da região e submetida previamente à caracterização bioquímica, molecular e testada frente a diferentes antimicrobianos. O cultivo bacteriológico do leite foi realizado seguindo as recomendações de Quinn (1994), nos momentos que antecederam o diagnóstico clínico da mastite (Grunert 1993). 
Os animais foram acompanhados clinicamente pela manhã e a tarde. Após o diagnóstico da mastite, procedeu-se a colheita do material biológico para as análises nos momentos $12 \mathrm{~h}, 24 \mathrm{~h}$, 36h, 48h, 60h, 72h, 84h, 96h, 108h, 120h, 132h, 168h, 180h, $288 \mathrm{~h}$ e $336 \mathrm{~h}$ após a inoculação (p.i.). Após o surgimento da infecção e o diagnóstico bacteriológico positivo, foi instituído o tratamento, às $36 \mathrm{~h}$ p.i., depois da ordenha da tarde com três aplicações de antimicrobiano intramamário ${ }^{7}$ e sistêmico ${ }^{8}$, com intervalos de $24 \mathrm{~h}$, associado à flunixin meglumine ${ }^{9}$. As ovelhas foram submetidas ao exame clínico, inclusive da glândula mamária de acordo com as recomendações de Grunert (1993) e Radostitis et al. (2000).

Colheita das amostras. As amostras de sangue para a determinação do teor plasmático do fibrinogênio foram colhidas mediante punção da veia jugular em tubos contendo EDTA. Para obtenção do soro, foram utilizados tubos siliconizados sem anticoagulante, que foram centrifugados a $1600 \mathrm{G}$ durante cinco minutos. As amostras foram distribuídas em alíquotas e mantidas a $-20^{\circ} \mathrm{C}$ para posterior análise laboratorial.

Exames laboratoriais. O teor plasmático de fibrinogênio foi determinado pelo método de precipitação pelo calor $\left(56-58^{\circ} \mathrm{C}\right)$ e leitura realizada em refratômetro ${ }^{10}$, conforme preconizado por Jain (1993). A concentração sérica de proteína total foi obtida pelo método do biureto, empregando-se kit comercial ${ }^{11}$. A separação das frações protéicas foi realizada por meio de eletroforese em gel de poliacrilamida contendo dodecil sulfato de sódio (SDS-PAGE), conforme técnica descrita por Laemmli (1970). As concentrações protéicas foram mensuradas em densitômetro computadorizado ${ }^{12}$. Como referência foi utilizada solução marcadora ${ }^{13} \mathrm{com}$ pesos moleculares 29.000, 45.000, $66.000,97.400,116.000$ e 205.000 dáltons (D), além das proteínas purificadas haptoglobina, ceruloplasmina, transferrina, $\alpha 1$-antitripsina, albumina e lgG. A preparação das amostras de soro sanguíneo para determinação das concentrações séricas de $\mathrm{Cu}$, Fe e Zn seguiu as recomendações de Milles et al. (2001) com leitura em espectrofotômetro de absorção atômica (EAA) ${ }^{14}$.

Análise estatística. Os dados foram submetidos à análise de variância (Teste F) utilizando-se o procedimento GLM do SAS (SAS, 2000), com contraste de médias pelo teste de Duncan. Também foram efetivadas análises de regressão ajustadas em função dos momentos experimentais e determinação dos coeficientes de correlação para verificar a relação entre pares de variáveis. A significância obtida na regressão foi avaliada por meio do Teste F (Sampaio, 1998). Foi adotado o nível de significância $(\mathrm{P})$ de $5 \%$. Os dados foram analisados por meio do programa computacional Statistical Analysis System (SAS).

O trabalho obteve parecer favorável da Comissão de Ética em Experimentação Animal (CEEA Of. n¹8/06), Centro de Ciências Biológicas/Universidade Federal de Pernambuco (Lei

\footnotetext{
${ }^{7}$ Gentocin ${ }^{\circledR}$ Mastite 250mg, Intervet/Schering Plough Animal Health, Av. Sir Henry Wellcome 335, Cotia, SP, Brasil.

${ }^{8}$ Gentocin ${ }^{\circledR}$ Solução injetável 40mg, Intervet/Schering Plough Animal Health, Av. Sir Henry Wellcome 335, Cotia, SP.

${ }^{9}$ Banamine ${ }^{\circledR}$ Intervet/Schering Plough Animal Health, Av. Sir Henry Wellcome 335, Cotia, SP.

10 Quimis, Rua Gema 278/308, Diadema, SP, Brasil.

11 Proteínas Totais, Labtest, Av. Paulo Ferreira da Costa 600, Lagoa Santa, Belo Horizonte, MG, Brasil.

12 Shimadzu CS 9301, Shimadzu Corporation, Tokyo, Japan.

${ }^{13}$ Sigma-Aldrich, 3050 Spruce Street, St Louis, MO, USA.

${ }^{14}$ Varian, Model SpectrAA 220.
}

9.605, Art.32, e Decreto 3.179, Art.17 de 21.09.99), estando de acordo com as normas sugeridas pelo COBEA e com as normas internacionais estabelecidas pelo National Institute of Health Guide for Care and Use of Laboratory Animals.

\section{RESULTADOS}

Todas as glândulas inoculadas apresentaram mastite clínica aguda. Das dez ovelhas, oito desenvolveram a forma gangrenosa, uma evoluiu para a forma crônica, com fibrose do parênquima mamário e a outra morreu $48 \mathrm{~h}$ após a inoculação. A bactéria inoculada foi re-isolada do leite $24 \mathrm{~h}$ p.i. em todas as mamas comprometidas. Após o tratamento verificou-se em algumas ovelhas o retorno gradativo à normalidade dos indicadores clínicos sistêmicos (comportamento, apetite, coloração das mucosas, temperatura corpórea, freqüência cardíaca, freqüência respiratória e dinâmica ruminal), no entanto a infecção ocasionou perda total da funcionalidade da glândula mamária.

Proteinograma. Os valores médios das concentrações séricas de proteína total e das proteínas identificadas no traçado eletroforético nos diferentes momentos experimentais são mostrados no Quadro 1. A técnica de eletroforese em gel de poliacrilamida (SDS-PAGE) permitiu o fracionamento de 23 proteínas, cujos pesos moleculares $(P M)$ variaram de 26.000 a 185.000 dáltons $(D)$, sendo possível identificar imunoglobulina $A(P M=143.000 \mathrm{D})$, ceruloplasmina $(P M=115.000 \mathrm{D})$; transferrina $(P M=85.000$ $D)$, hemopexina $(P M=79.000 \mathrm{D})$; albumina $(P M=66.000$ $D), \alpha 1$-antitripsina $(P M=60.000 \mathrm{D})$, haptoglobina $(P M=45.000 \mathrm{D}), \alpha 1$-glicoproteína ácida $(P M=40.000 \mathrm{D})$ e imunoglobulina $\mathrm{G}(\mathrm{PM}=36.000 \mathrm{D})$, bem como outras proteínas identificadas pelos respectivos pesos moleculares.

As concentrações plasmáticas do fibrinogênio revelaram variações significativas a partir das $48 \mathrm{~h}$ p.i. $(P<0,05)$ em relação ao momento controle, atingindo o valor máximo $(933,33 \mathrm{mg} / \mathrm{dL})$ às $132 \mathrm{~h}$ p.i.. A partir deste momento, verificou-se decréscimo na concentração desta proteína. A análise de relação entre a albumina e o fibrinogênio plasmático demonstrou alta relação negativa $(r=-0,60)$, no entanto verificou-se alta correlação positiva entre este marcador inflamatório amplamente empregado em ruminantes com a ceruloplasmina $(r=0,74)$ (Fig.1), haptoglobina $(r=0,62)$ (Fig.2) e $\lg A(r=0,63)$ (Fig.3).

Alta relação negativa $(r=-0,68)$ foi registrada entre os teores séricos de ceruloplasmina com a albumina e positiva $(r=0,65)$ com a IgA (Fig.4), paralelamente alta correlação positiva foi verificada entre a concentração de antitripsina com IgG $(r=0,94)$ nas ovelhas infectadas experimentalmente por Staphylococcus aureus.

Minerais. Com a manifestação clínica da mastite, observada já às 24 h p.i., constatou-se elevação significativa $(\mathrm{P}<0,05)$ nos teores séricos do $\mathrm{Cu}$, que de forma progressiva alcançou valor máximo de $1,29 \mathrm{mg} / \mathrm{L}$ às $168 \mathrm{~h} \mathrm{p.i.} \mathrm{man-}$ tendo-se elevado até o término do período de observação (Quadro 2). As concentrações séricas de Fe elevaram-se discretamente 12 horas p.i., e a partir de 24 horas p.i. decresceram $(P<0,05)$, notando-se os menores valores nes- 


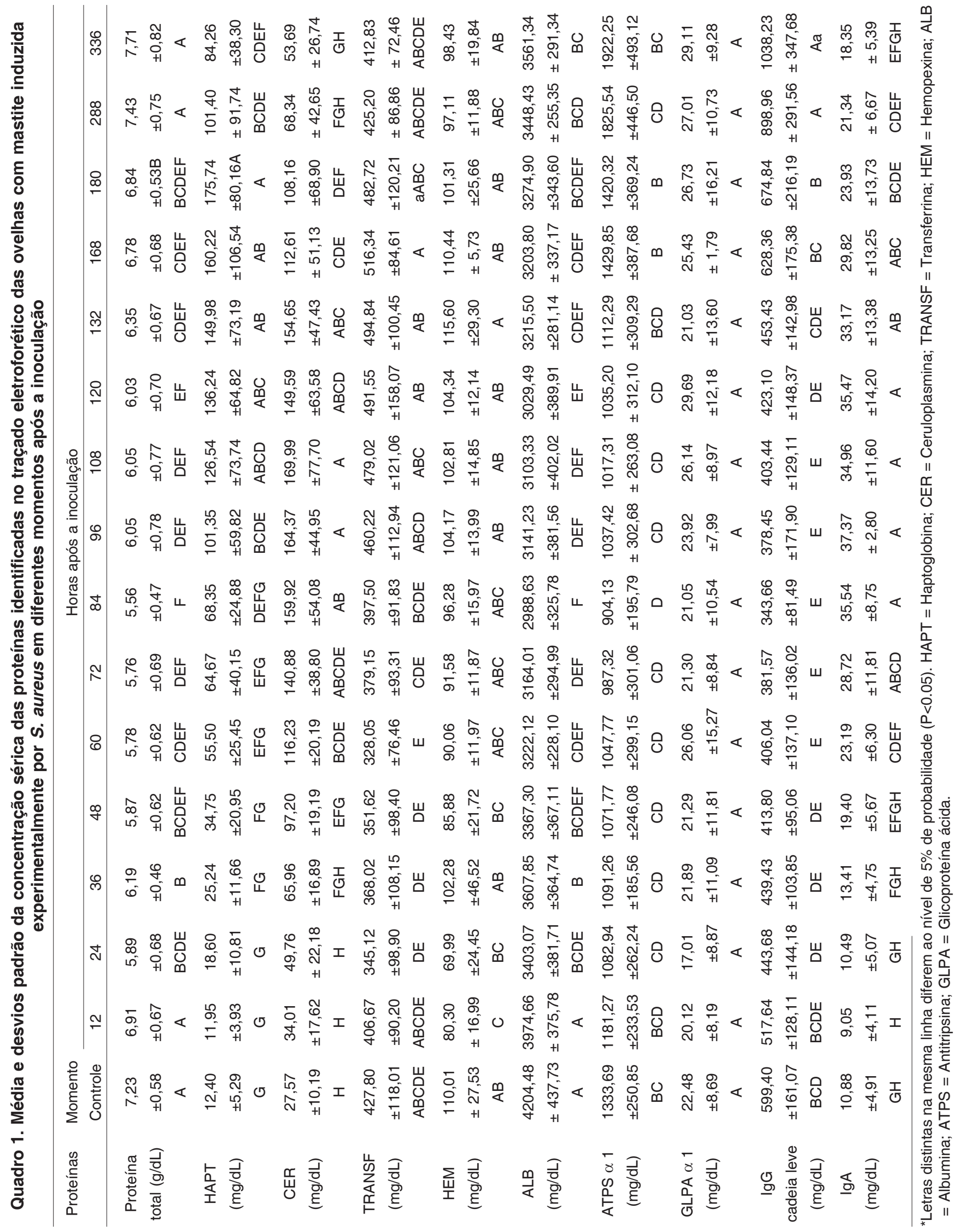




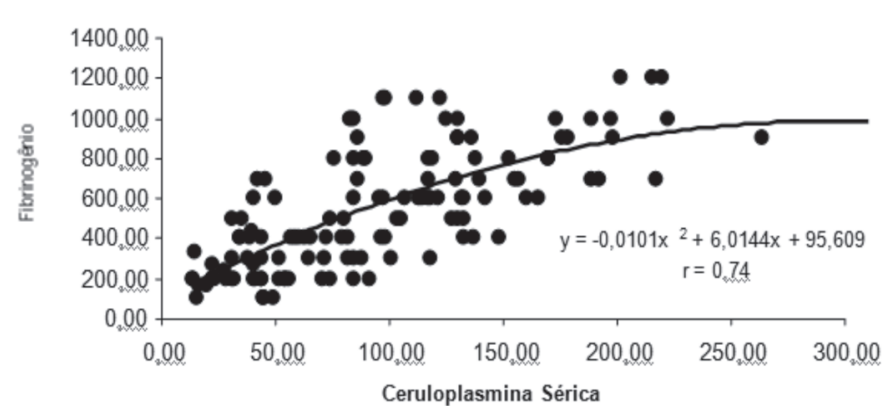

Fig.1. Relação entre ceruloplasmina (mg/dL) e fibrinogênio (mg/ $\mathrm{dL}$ ) em ovelhas com mastite induzida por Staphylococcus aureus em diferentes momentos após a infecção.

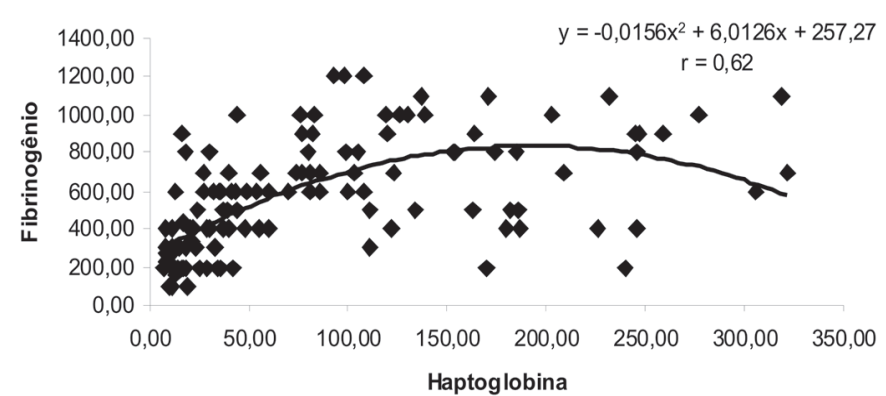

Fig.2. Relação entre haptoglobina $(\mathrm{mg} / \mathrm{dL})$ e fibrinogênio $(\mathrm{mg} /$ $\mathrm{dL}$ ) em ovelhas com mastite induzida por Staphylococcus aureus em diferentes momentos após a infecção.

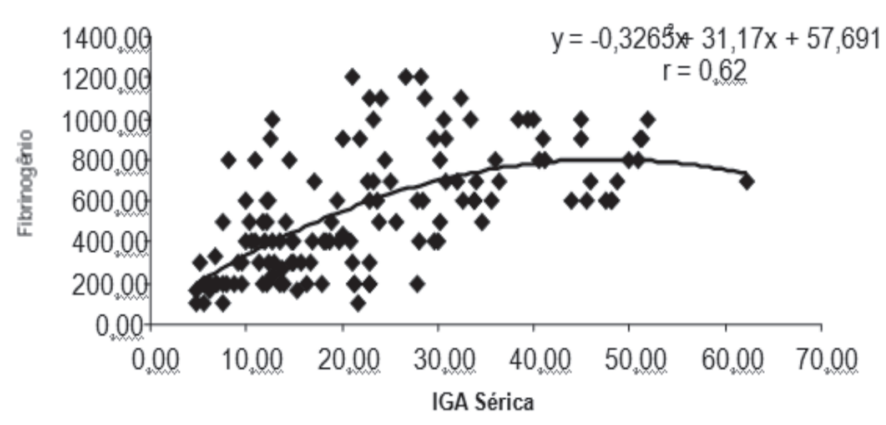

Fig.3. Relação entre $\operatorname{lgA}(\mathrm{mg} / \mathrm{dL})$ e fibrinogênio $(\mathrm{mg} / \mathrm{dL})$ em ovelhas com mastite induzida por Staphylococcus aureus em diferentes momentos após a infecção.

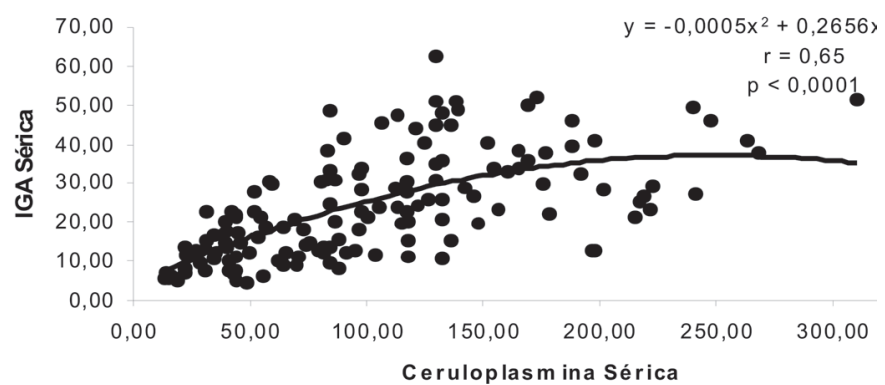

Fig.4. Relação entre ceruloplasmina (mg/dL) e $\operatorname{lgA}(\mathrm{mg} / \mathrm{dL})$ em ovelhas com mastite induzida por Staphylococcus aureus em diferentes momentos após a infecção.

te momento $(2,25 \mathrm{mg} / \mathrm{L})$, mantendo-se inferior ao estabelecido antes da infecção até 180 horas p.i. A partir de então verificou-se tendência de retorno dos teores séricos deste mineral ao valor do momento controle (Quadro 2). Constatou-se diminuição significativa nas concentrações de Zn a partir de 24 h p.i. $(P<0,05)$, com menor valor entre este momento e 36 horas p.i. (0.46mg/L). Posteriormente, ocorreu elevação gradativa nos dois últimos momentos experimentais (288h e 336h) os teores séricos foram semelhantes aos dos momentos iniciais (Quadro 2).

\section{DISCUSSÃO}

Proteinograma. A técnica de eletroforese permitiu o fracionamento de 23 proteínas, inclusive com identificação e quantificação de proteínas de fase aguda (PFA) e de imunoglobulinas ( $\lg G$ e $\lg A$ ). Como mencionado por diferentes autores, o fracionamento eletroforético em SDSPAGE é um método confiável, de execução relativamente simples e de baixo custo, que permite a detecção de concentrações protéicas muito baixas e a identificação de 20 a 30 tipos diferentes de proteínas, diferentemente do uso de filmes de agarose ou de acetato de celulose, que possibilita a identificação de cinco a sete bandas protéicas (Gordon 1975, Mendonça et al. 2002, Fagliari et al. 2003).

Nos estágios iniciais da reação inflamatória da glândula mamária, desencadeada por Staphylococcus aureus ocorreram alterações consideradas próprias de resposta de fase aguda da inflamação, sendo uma de suas carac-

Quadro 2. Média e desvios padrão dos teores séricos ( $\mu \mathrm{g} / \mathrm{dL})$ de cobre, ferro e zinco $(\mu \mathrm{g} / \mathrm{dL})$ das ovelhas com mastite induzida experimentalmente por Staphylococcus aureus em diferentes momentos após a inoculação

\begin{tabular}{|c|c|c|c|c|c|c|c|c|c|c|c|c|c|c|c|c|}
\hline & \multirow{2}{*}{$\begin{array}{c}\text { Momento } \\
\text { Controle }\end{array}$} & \multicolumn{15}{|c|}{ Horas após a inoculação } \\
\hline & & 12 & 24 & 36 & 48 & 60 & 72 & 84 & 96 & 108 & 120 & 32 & 168 & 80 & 88 & 336 \\
\hline & & $\begin{array}{c} \pm 0,16 \\
\text { EF }\end{array}$ & $\mathrm{F}$ & 0 & & $\begin{array}{c}0,94 \\
\pm 0,25 \\
\text { CDEF }\end{array}$ & $\begin{array}{c}0,95 \\
\pm 0,29 \\
\text { BCDEF }\end{array}$ & & $\begin{array}{c}1,03 \\
\pm 0,36 \\
\text { ABCD }\end{array}$ & & & & & & & \\
\hline & $\begin{array}{c}3,15 \\
\pm 0,61 \\
\text { AB }\end{array}$ & $\begin{array}{c}3,41 \\
\pm 0,19 \\
A\end{array}$ & $\begin{array}{c}2,25 \\
\pm 0,42 \\
\mathrm{C}\end{array}$ & $\begin{array}{c}2,34 \\
\pm 0,55 \\
\text { C }\end{array}$ & $\begin{array}{c}2,32 \\
\pm 0,48 \\
\mathrm{C}\end{array}$ & $\begin{array}{c}2,32 \\
\pm 0,52 \\
\mathrm{C}\end{array}$ & $\begin{array}{c}2,29 \\
\pm 0,40 \\
\quad C\end{array}$ & $\begin{array}{c}2,35 \\
\pm 0,52 \\
C\end{array}$ & $\begin{array}{c}2,31 \\
\pm 0,49 \\
\mathrm{C}\end{array}$ & $\begin{array}{c}2,35 \\
\pm 0,55 \\
\quad \mathrm{C}\end{array}$ & $\begin{array}{c}2,29 \\
\pm 0,51 \\
\text { C }\end{array}$ & & $\begin{array}{c}2,43 \\
\pm 0,68 \\
C\end{array}$ & $\begin{array}{c}2,37 \\
\pm 0,65 \\
\text { C }\end{array}$ & & $\begin{array}{c}2,68 \\
\pm 0,86 \\
B C\end{array}$ \\
\hline Zinco & $\begin{array}{c}1,14 \\
\pm 0,21 \\
\text { A }\end{array}$ & $\begin{array}{c}1,07 \\
\pm 0,26 \\
A B\end{array}$ & $\begin{array}{c}0,46 \\
\pm 0,10 \\
E\end{array}$ & $\begin{array}{c}0,46 \\
\pm 0,09 \\
E\end{array}$ & $\begin{array}{c}0,58 \\
\pm 0,22 \\
D E\end{array}$ & $\begin{array}{c}0,55 \\
\pm 0,11 \\
D E\end{array}$ & $\begin{array}{c}0,64 \\
\pm 0,35 \\
\text { CDE }\end{array}$ & $\begin{array}{c}0,57 \\
\pm 0,10 \\
\text { DE }\end{array}$ & $\begin{array}{c}0,66 \\
\pm 0,21 \\
\text { CDE }\end{array}$ & $\begin{array}{c}0,65 \\
\pm 0,13 \\
\text { CDE }\end{array}$ & $\begin{array}{c}0,69 \\
\pm 0,15 \\
\text { CDE }\end{array}$ & $\begin{array}{c}0,88 \\
\pm 0,49 \\
A B C\end{array}$ & $\begin{array}{c}0,82 \\
\pm 0,36 \\
\text { BED }\end{array}$ & $\begin{array}{c}0,99 \\
\pm 0,26 \\
A B\end{array}$ & $\begin{array}{c}1,10 \\
\pm 0,29 \\
\text { A }\end{array}$ & $\begin{array}{c}1,02 \\
\pm 0,19 \\
\text { AB }\end{array}$ \\
\hline
\end{tabular}

* Letras distintas na mesma linha diferem ao nível de $5 \%$ de probabilidade $(P<0.05)$. 
terísticas a ambiguidade de resposta de dois grupos distintos de proteínas de origem hepática, ou seja, as PFAs positivas, como haptoglobina, ceruloplasmina, hemopexina, $\alpha 1$-antitripsina e $\alpha 1$-glicoproteína ácida, cujos teores se elevam durante inflamação e as PFAs negativas, como transferrina e albumina, cujas concentrações decrescem. Segundo Jain (1993) este tipo de resposta é mediada pela ação de citocinas pró-inflamatórias liberadas nos estágios iniciais da infecção.

Haptoglobina. Constatou-se a elevação do teor sérico de haptoglobina já nas primeiras 24 horas p.i., com valor máximo de $175,74 \mathrm{mg} / \mathrm{dL}$ às $180 \mathrm{~h}$ p.i., ou seja, cerca de 14 vezes superior ao encontrado no momento controle, elevação esta que apesar de significativa, foi inferior àquela relatada por Salonen et al. (1996), que verificaram aumento superior 50 vezes em resposta à mastite experimental por Escherichia coli em vacas. Esta diferença provavelmente está relacionada ao agente etiológico envolvido, pois E. coli, uma bactéria Gram-negativa, induz forte estímulo para a síntese hepática desta PFA (Sandholm, 1995). O aumento notado a partir de $24 \mathrm{~h}$ p.i. foi semeIhante ao relatado por Pepin et al.(1991) em infecção experimental por C. pseudotuberculosis em ovinos mostrando a importância desta PFA como indicador de doença inflamatória em ovinos, porém são escassos os trabalhos relacionados a esta proteína nesta espécie, particularmente em casos de mastite estafilocócica. A grande maioria da literatura é baseada em estudos sobre a mastite em vacas, sendo nesta espécie animal, considerada melhor indicador de inflamação do que o leucograma (Jain, 1993). Em bovinos, Pachauri et al. (2002) sugeriram haver correlação direta entre o seu teor plasmático e a extensão da lesão no tecido mamário. Os resultados observados no presente trabalho reforçam os relatos de Skinner \& Roberts (1994), mencionando que esta PFA pode ser utilizada como indicador de infecção bacteriana/inflamação em ovelhas. Os resultados encontrados sugerem a aplicabilidade da mensuração desta proteína no diagnóstico precoce de mastite estafilocócica em ovelhas.

Ceruloplasmina. A elevação do teor sérico de ceruloplasmina, seis vezes superior ao observado no momento controle, coincidiu com a maior gravidade do quadro clínico 24h p.i. O aumento da concentração desta proteína pode ser justificada por sua ação antiinflamatória e biocatalisadora (Chassagne et al. 1998, Patel et al. 2002). Apesar de não ser encontrada na literatura consultada informação quanto à resposta da ceruloplasmina em caso de mastite em ovelha infectada por $S$. aureus, há relatos de elevação desta PFA em outras enfermidades nesta espécie, bem como em bovinos (Chassagne et al. 1998, Pfeffer \& Rogers 1989, Pfeffer et al. 1993, Fagliari et al. 2003). Embora a utilização da ceruloplasmina como marcador inflamatório seja menos comum que a de outras PFAs, como a haptoglobina (Murata et al., 2004), os resultados obtidos neste experimento, reforçam a importância deste biomarcador em doenças inflamatórias/infecciosas conforme já mencionado por Pfeffer et al. (1993).
Transferrina. A diminuição dos teores séricos de transferrina até 60 horas p.i. a caracterizam como proteína de fase aguda negativa, conforme citado por Jain (1993) e Sandholm (1995) em casos de mastite clínica em vacas. Tal redução desta PFA representa um mecanismo de defesa do animal, considerando que esta proteína sequestra íons férricos, que podem servir como substrato para diversos microrganismos (Murata et al. 2004). Acredita-se que esta função bacteriostática da transferrina esteja relacionada à maior avidez desta pelo $\mathrm{Fe}$ em $\mathrm{pH}$ 6,4 a 6,7, facilitando a transferência deste microelemento do plasma para o leite (De Jong et al., 1990). Sabe-se que a glândula mamária da vaca aumenta a síntese de lactoferrina quando exposta a bactérias, sendo relatado que alto teor de lactoferrina na glândula mamária de vacas secas contribui para a resistência à invasão de patógenos (Smith \& Schanbacher 1977). Para Tizard (2002), a concentração de transferrina aumenta quando há diminuição do teor sérico de ferro, situação que pode ocorrer nas infecções causadas por $S$. aureus, que necessita deste mineral para sua multiplicação, conforme também evidenciado neste estudo.

Hemopexina. As informações referentes à hemopexina nas espécies animais, particularmente nos ruminantes, são bastante escassas. O decréscimo observado nas primeiras 24 horas após a infecção intra-mamária poderia estar relacionado a um mecanismo de defesa do animal, pela capacidade desta glicoproteína se ligar à fração heme da hemoglobina, indisponibilizando o ferro aos patógenos, conforme relata Jain (1993).

Albumina. A diminuição dos teores de albumina nos momentos subseqüentes à indução de mastite pode ser justificada pelo fato de ser esta uma proteína de fase aguda negativa, conforme descrito por Jain (1993). O discreto aumento dos teores de albumina a partir de 96 horas p.i., com tendência de retorno aos valores basais, coincidiu com o restabelecimento clínico dos animais.

$\alpha 1$-Antripsina. Os resultados verificados divergem dos encontrados por Fagliari et al. (2003), que constataram elevações significativas da concentração de $\alpha_{1}$ antitripsina em bezerros com pasteurelose pneumônica experimental. A $\alpha 1$-antripsina é a principal inibidora de protease circulante, que protege tecidos contra a ação da elastase neutrofílica, impedindo a ocorrência de lesão tecidual (Murata et al., 2004). Com base nos resultados, é provável que esta proteína não seja relevante como marcador de inflamação intramamária induzida por $S$. aureus em ovelhas, pois apesar do inóculo empregado ter ocasionado mastite aguda, com graves repercussões sistêmicas, estas não foram suficientes para induzir elevação desta proteína nos momentos iniciais de observação. Murata et al. (2004), afirmaram que o valor diagnóstico desta proteína em medicina veterinária ainda é questionável, daí a importância de estudo mais detalhado do perfil de $\alpha 1$-antripsina em ruminantes enfermos, particularmente ovinos.

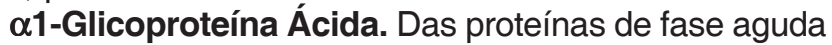
identificadas no traçado eletroforético, esta glicoproteína, 
também conhecida como seromucóide, foi a única que não apresentou alterações durante o estudo, diferindo das citações da literatura, onde é relatada como PFA empregada para monitorar doenças inflamatórias em diferentes espécies animais (Eckersall et al. 2001, Fagliari et al. 2003) e considerada por Murata et al. (2004) importante biomarcador no monitoramento clínico de processos inflamatórios de bovinos. Os resultados divergem dos encontrados por Fagliari et al. (2003), que trabalhando com bovinos, verificaram após quatro a seis horas da inoculação intrabronquial de Mannheimia (Pasteurella) haemolytica aumento superior a $400 \%$ na concentração desta proteína. Da mesma forma, Regassa et al. (2002), estudando ovelhas com metrite induzida, verificaram teores elevados desta PFA por até duas semanas após a infecção.

Imunoglobulinas. A técnica de eletroforese em SDSPAGE permitiu identificar e quantificar IgG e IgA. O discreto decréscimo na concentração da IgG no soro nos primeiros dias após a infecção pode estar relacionado à migração desta imunoglobulina para a glândula mamária na tentativa de auxiliar no controle da infecção e a posterior elevação observada a partir do quinto dia pós-infecção, provavelmente em razão do estímulo antigênico desencadeado por Staphylococcus aureus. Para Sandholm \& Korhonen (1995) o sistema imune da glândula mamária consiste de ambos os componentes humoral e celular. As imunoglobulinas as quais, detém a atividade anticorpo específica contra estímulos antigênicos são responsáveis pelo componente humoral.

O aumento do teor sérico de IgA pode estar relacionado à demanda orgânica, tendo em vista a importância desta classe de imunoglobulinas na proteção de superfícies corpóreas, dentre estas a glândula mamária, contra a invasão de agentes infecciosos, impedindo a aderência de bactérias (Jain 1993). O momento em que a concentração desta classe de imunoglobulina começa a decrescer coincide com o aumento do teor sérico de IgG. A concentração de $\lg A$ mostrou correlação positiva com fibrinogênio $(r=0,63)$ (Fig.3) e ceruloplasmina ( $r=0,65)$ (Fig.4), ambas PFAs positivas, podendo talvez ser esta imunoglobulina um indicador precoce de infecção mamária de ovelhas.

Fibrinogênio. A hiperfibrinogenemia verificada 60 a 180 horas p.i. foi indicativo de uma reação inflamatória, que conforme relatado por Jain (1993), esta proteína se eleva como resposta ao estímulo das interleucinas IL-1, IL-6 e fator de necrose tumoral. Este mesmo autor relata que entre 24 e 36 horas após a lesão tecidual, a concentração de fibrinogênio se eleva precedendo qualquer aumento na concentração de gama globulina, corroborando com o observado neste estudo, no qual o início do aumento significativo do teor de fibrinogênio foi verificado 36 horas p.i.. A determinação do teor de fibrinogênio tem sido utilizada em ovinos como indicador confiável de inflamação ou infecção bacteriana (Pfeffer et al. 1993), como observado neste experimento, onde notou-se hiperfibrinogenia até a regressão dos sinais clínicos. Verificou-se alta correlação entre fibrinogênio e ceruloplasmina ( $r=0,74)$ (Fig.2) e haptoglobina $(r=0,62)$ (Fig.1), ambas reconhecidas como importantes PFAs de ruminantes, possibilitando ratificar a utilização desta proteína plasmática como marcador inflamatório de mastite estafilocócica em ovelhas.

Minerais. As informações relacionadas às alterações dos teores séricos de cobre nos casos de mastite causada por $S$. aureus em ovelhas são escassas, sendo mais comuns relatos em vacas. O aumento marcante do teor sérico de cobre observado neste estudo, também foram notados em vacas e cabras com mastite experimental por Escherichia coli e S. aureus (Van Miert et al. 1983). Por outro lado, Middleton et al. (2004) verificaram diminuição do teor sérico deste elemento em vacas com mastite experimental por $S$. aureus, atribuindo ao fato da infecção ocorrida na glândula mamária ter sido branda, com pouca influência sistêmica. Em ovelhas com casos subclínicos de mastite, Lamand \& Levieux (1981), verificaram hipercupremia significativa que persistiu por longo tempo, mesmo durante o período de convalescença dos animais após o tratamento. Um fator que pode explicar o aumento da concentração sérica de Cu nas ovelhas com mastite é a relação do mineral com a ceruloplasmina, uma PFA que transporta cerca de $90 \%$ de Cu presente no plasma. A diminuição evidente dos valores de ferro e zinco no soro também foi relatada por outros autores, em maior ou menor intensidade, nos casos de mastite em vacas, cabras e ovelhas, o que corrobora os resultados deste estudo. Estes minerais reagem à resposta inflamatória, iniciada pela liberação de mediadores inflamatórios, em especial as IL 1, IL 6 e fator de necrose tumoral, que removem ferro e zinco da circulação e direcionam-os ao fígado, acarretando menor disponibilidade destes elementos aos microrganismos causadores de mastite (Lamand \& Levieux 1981, Van Miert et al. 1983, Middleton et al. 2004, Yildiz \& Kaygusuzoglu 2005). Além desta ação, as citocinas são responsáveis pela maioria dos sinais observados na inflamação, bem como a mobilização celular na glândula mamária (Sandholm 1995, Tizard 2002). Ademais, após a invasão bacteriana, cessa a absorção de ferro e zinco. As citocinas produzidas por macrófagos estimulam a secreção de transferrina e haptogloblina pelos hepatócitos e aumento do armazenamento de ferro no fígado, reduzindo a disponibilidade deste microelemento e consequentemente retardando a multiplicação bacteriana (Sandholm 1995). Resultados semelhantes foram relatados por Burriel \& Heys (1997), em ovelhas com infecção intramamária causada por Staphyloccocus coagulase negativa. Apesar de Middleton et al. (2004) concluírem que o processo de indisponibilização de minerais como um mecanismo de defesa inespecífico na mastite por $S$. aureus ser menos acentuado do que aquele relacionado a infecções por bactérias Gram-negativas, como E. coli, neste estudo ficou bem caracterizado a potente ação local do $S$. aureus na glândula mamária de ovelhas e sua repercussão sistêmica ratificando a importância da ceruloplasmina, haptoglobina e fibrinogênio plasmático 
como indicadores precoce da mastite em ovelhas, bem como a alteração na concentração sérica dos minerais, caracterizada pelo decrécimo do Ferro e Zinco e elevação do cobre.

Agradecimentos.- Ao MCT/CNPq, pelo suporte financeiro (Proc. 474389/03), e à Dra Nilma C. Leal (Aggeu Magalhães/Fiocruz, Recife), pela caracterização bioquímica e molecular da amostra de Staphylococcus aureus. Os autores prestam homenagem póstuma ao Dr. Luis Carlos Valeriano Simão, pela dedicação e presteza na execução do delineamento experimental deste trabalho.

\section{REFERÊNCIAS}

Burriel A.R. \& Heys V. 1997. Serum and milk iron levels during sheep intramammary infection caused by coagulase-negative staphylococci. Biol. Trace Element Res. 59(1/3):153-158.

Chassagne M., Barnouin J. \& Chacornac J.P. 1998. Biological predictors for early clinical mastitis occurrence in Holstein cows under field conditions in France. Prev. Vet. Med. 35:29-38.

Corrigall W., Dalgarno A.C., Ewen L.A. \& William S.R.B. 1976. Modulation of plasma copper and zinc concentrations by disease states in ruminants. Vet. Rec. 99:396-397.

De Jong G., Van Dijk J.P. \& Van Eijk H.G. 1990. The biology of transferrin. Clinica Chimica Acta 190:1-46

Eckersall P.D., Young F.J., McComb C., Hogarth C.J., Safi S., Weber A., McDonald T., Noland A.M. \& Fitzpatrick J.L. 2001. Acute phase proteins in serum and milk from dairy cows with clinical mastitis. Vet. Rec. 148:35-41.

Fagliari J.J., Weiss D.J., McClenanhan D.M. \& Evanson O.A. 2003. Serum protein concentrations in calves with experimentally induced pneumonic pasteurellosis. Arq. Bras. Med. Vet. Zootec. 55(4):383-387.

Fonseca L.F.L. \& Santos M.V. 2001. Manejo de Ordenha: Princípios e Métodos, p.59-63. In: Ibid. (Eds), Qualidade do Leite e Controle de Mastite. Lemos Editorial, São Paulo.

Ganheim C., Alenius S. \& Waller K.P. 2007. Acute phase proteins as indicators of calf herd health. Vet. J. 173:645-651.

Gordon A.H. 1975. Electrophoresis of proteins in polyacrylamide and starch gels. Elsevier Science Publishers, New York. 213p

Grönlund U., Hultén C., Eckersall P.D., Hogarth C. \& Waller K.P. 2003. Haptoglobin and serum amyloid a in milk and serum during acute and chronic experimentally induced Staphylococcus aureus mastitis. J. Dairy Res. 70:379-386.

Grunert E. 1993. Sistema genital feminino, p.299-308. In: Dirksen G., Gründer H.D. \& Stöber M. (Eds), Rosenberger, Exame Clínico dos Bovinos. $3^{\mathrm{a}}$ ed. Guanabara Koogan, Rio de Janeiro.

Jain N.C. 1993. Essentials of Veterinary Hematology. Lea and Febiger, Philadelphia. 417p.

Laemmli U.K. 1970. Cleavage of structural proteins during the assembly of the head of bacteriophage T4. Nature 227:680-685.

Lamand M. \& Levieux D. 1981. Effects of infection on plasma levels of copper and zinc in ewes. Ann. Rech. Vét. 12(2):133-136.

Mendonça C.L., Kohayagawa A., Schenk M.A.M., Madruga C.R., Vieira D., Afonso J.A.B. \& Carvalho C.M.E. 2002. Perfil eletroforético das proteínas séricas de bezerros Nelores infectados experimentalmente com isolados de Babesia bigemina das regiões Sudeste, Nordeste e Norte do Brasil. Ciênc. Vet. Trop. 5(2/3):76-85.

Mendonça C.L., Afonso J.A.B. \& Costa N.A. 2005. Mastite em ovelhas. Vet. Zootec., Recife, 25:7.

Menzies P.I. \& Ramanoon S.Z. 2001. Mastitis of sheep and goats. Vet. Clin. North Am., Food Anim. Pract. 17:333-358.

Middleton J.R., Luby C.D., Viera L., Tyler J.W. \& Casteel S. 2004. Influence of Staphylococcus aureus intramammary infection on serum copper, zinc, and iron concentrations. J. Dairy Sci. 87:976-979.
Milles P.N., Wilkinson S. \& McDowell L.R. 2001. Analysis of mineral for animal nutrition research. $3^{\text {rd }}$ ed. Department of Animal Sciences/ USDA/T-STAR, University of Florida. 118p.

Murata H., Shimada N. \& Yoshioka M. 2004. Current research on acute phase proteins in veterinary diagnosis: An overview. Vet. J. 168:28-40.

Oliveira L.G.L. 2007. Estudo clínico-epidemiológico e bacteriológico da mastite em ovelhas da raça Santa Inês no Agreste Meridional do Estado de Pernambuco. Dissertação de Mestrado, Universidade Federal Rural de Pernambuco, Recife. 47p.

Pachauri S.P., Gupta M. \& Singh V.S. 2002. Serum haptoglobin concentrations in crossbred cows with mastitis. Indian J. Anim. Sci. 72(1): 55-56.

Patel B.N., Dunn R.J., Jeong S.Y., Zhu Q., Julien J.P. \& David S. 2002. Ceruloplasmin regulates iron levels in the CNS and prevents free radical injury. J. Neurosci. 22:6578-6586.

Pépin M., Pardon P., Lantier F., Marly J., Levieux D. \& Lamand M. 1991. Experimental Corynebacterium pseudotuberculosis infection in lambs: Kinetics of bacterial dissemination and inflammation. Vet. Microbiol. 26(4):381-392

Pfeffer A. \& Rogers K.M. 1989. Acute phase response of sheep: Changes in the concentrations of ceruloplasmin, fibrinogen, haptoglobin and major blood cell types associated with pulmonary damage. Res. Vet. Sci. 46:118.

Pfeffer A., Rogers K.M., O'Keeffe L. \& Osborn P.J. 1993. Acute phase protein response, food intake, liveweight change and lesions following intrathoracic injection of yeast in sheep. Res. Vet. Sci. 55(3):360-366.

Quinn P.J., Carter M.E., Markey B. \& Carter G.R. 1994. Clinical Veterinary Microbiology. Mosby, Philadelphia. 648p.

Radostits O.M., Gay C.C. \& Hinchcliff, K.W. \& Constable P.D. 2007. Veterinary Medicine. $10^{\text {th }}$ ed. Saunders Elsevier, London. 2156p.

Regassa F., Sheldon I.M. \& Noakes D.E. 2002. Effect of experimentally induced metritis on uterine involution, acute phase protein response and PGFM secretion in the postpartum ewe. Vet. Rec. 150:605-607.

Salonen M., Hirvonen J., Piörälä S., Sankari S. \& Sandholm M. 1996. Quantitative determination of bovine serum haptoglobin in experimentally induced Escherichia coli mastitis. Res. Vet. Sci. 60(1):8891.

Sampaio I.B.M. 1998. Estatística Aplicada à Experimentação Animal. Fundação de Ensino em Medicina Veterinária e Zootecnia, Belo Horizonte. 221p.

Sandholm M. 1995. Inflammation in mastitis, p.59-75. In: Sandholml M., Buzalski T.H., Kaartinen L. \& Pyorala S. (Eds), The Bovine Udder and Mastitis. Gummerus Kirjapaino, Helsinki. 312p.

Sandholm M. \& Korhonen H. 1995. Infection of the udder-inflamation antibacterial defence mechanisms of the udder, p.37-48. In: Sandholml M., Buzalski T.H., Kaartinen L. \& Pyorala S. (Eds), The Bovine Udder and Mastitis. Gummerus Kirjapaino, Helsinki. 312p.

Skinner J.G. \& Roberts L. 1994. Haptoglobin as an indicator of infection in sheep. Vet. Rec. 134(2):33-36.

Smith K.L. \& Schanbacher F.L. 1977. Lactoferrin as a factor of resistance to infection of the bovine mammary gland. J. Am. Vet. Med. Assoc. 170:1224-1227.

Tizard I.R. 2002. Imunologia Veterinária: uma introdução. 6르 ed. Roca, São Paulo. 532p.

Van Miert A.S.J.P.A.M., Van Duin C.T.M., Verheijden J.H.M. \& Schotman A.J.H. 1983. Staphylococcal enterotoxin B and Escherichia coli endotoxin: Comparative observations in goats on fever and associated clinical hematologic and blood biochemical changes after intravenous and intramammary administration. Am. J. Vet. Res. 44(6): 955-963.

Yildiz H. \& Kaygusuzoglu E. 2005. Investigation of Ca, Zn, Mg, Fe, and $\mathrm{Cu}$ concentrations in blood and milk of cow with negative and positive CMT results. Vet. Inst. Pulawy 49(2):209-213. 